\title{
PENGARUH PEER REVIEW TENTANG KESEHATAN REPRODUKSI TERHADAP SIKAP REMAJA TENTANG SEKSUAL PRANIKAH DI KELAS X. MIA I DAN XI. B SMAN 9 MATARAM
}

\author{
Suhartiningsih", Alwan Wijaya², Antoni Eka Fajar Maulana ${ }^{3}$, \\ I Putu Ari Wira Santika ${ }^{4}$ \\ 1,2,3,4 Program Studi Keperawatan \\ Sekolah Tinggi Ilmu Kesehatan (STIKES) Mataram \\ Email : ningsihsuharti86@gmail.com
}

\section{INTI SARI}

Masalah prilaku seksual yang menyimpang terjadi terutama dikalangan remaja, hal ini disebabkan karena kurangnya informasi yang diperoleh remaja mengenai kesehatan reproduksi. Data dari PKBI terdapat 37.000 kasus kehamilan yang tidak diinginkan $27 \%$ diantaranya belum menikah, termasuk $12,5 \%$ masih berstatus pelajar. Tujuan penelitian ini adalah untuk mengetahui peer review tentang kesehatan reproduksi terhadap sikap remaja tentang seksual pranikah dikelas X MIA I dan XI. B SMAN 9 Mataram.

Penelitian ini merupakan penelitian deskriptif analitik dengan metode survei dengan rancangan Cross Sectional. Teknik pengambilan sampel secara nonprobability sampling dengan sampling jenuh (total sampling), dengan jumlah responden sebanyak 60 orang. Metode pengumpulan data yang digunakan adalah penyebaran kuisioner. Analisa data menggunkan uji statistik korelasi spearman rank.

Hasil penelitian menunjukkan bahwa peer review tentang pengetahuan kesehatan reproduksi secara keseluruhan baik dan sikap remaja tentang seksual pranikah juga baik. Hasil penelitian menunjukkan ada pengaruh peer review tentang kesehatan reproduksi terhadap sikap remaja tentang seksual pranikah.

Peer review tentang kesehatan reproduksi di SMAN 9 Mataram di peroleh bahwa sebanyak 26 responden dalam kategori baik. Sikap remaja tentang seksual pranikah di SMAN 9 Mataram am di peroleh bahwa sebanyak 38 responden dalam kategori baik.

Kata Kunci: Peer review, hubungan seksual pranikah

\section{PENDAHULUAN}

Salah satu periode dalam rentang kehidupan individu adalah masa remaja. Masa remaja merupakan segmen kehidupan yang penting dalam siklus perkembangan individu, dan merupakan masa transisi yang dapat diarahkan kepada perkembangan masa dewasa yang sehat.

Menurut WHO, remaja adalah individu baik perempuan maupun laki-laki yang berusia 10-19 tahun, sedangkan menurut UN (united nations) remaja termasuk dalam kategori youth (anak muda) yaitu berusia 15-24 tahun.
Kemudian disatukan bahwa remaja atau kaum muda (young people) adalah mencakup usia 10-24 tahun (BKKBN NTB, tahun 2013)

Sebagaimana diketahui bahwa jumlah remaja umur 10-19 tahun di indonesia sekitar 40 juta $(19,61 \%)$ dari jumlah penduduk indonesia sebanyak 220 juta, yang terdiri dari remaja pria 5 persen dan remaja puteri $1 \%$ menyatakan secara terbuka bahwa mereka pernah melakukan hubungan seksual (Depkes, 2013). Berdasarkan data dari BKKBN NTB hasil 
pendataan keluarga tahun 2013, jumlah penduduk Nusa Tenggara 4.396.767 jiwa, sedangkan jumlah remaja umur 10-19 tahun 1.493.797 jiwa $(33,97 \%)$

Dewasa ini terdapat banyak masalah perilaku seksual yang menyimpang terjadi terutama dikalangan remaja, hal ini disebabkan karena kurangnya informasi yang diperoleh remaja mengenai kesehatan reproduksi.

Dikalangan remaja, teman sebaya menduduki peran penting dalam membicarakan kesehatan reproduksi remaja. Terlebih lagi setelah melihat pergaulan remaja siswa/siswi SMAN 9 Mataram melalui survei pendahuluan, dari beberapa sumber informasi seperti televisi, video, film, majalah, komputer, telpon genggam dan teman. Yang sangat berpengaruh dalam penyampaian informasi adalah peran teman. Sehingga dalam hal ini teman sebaya mempunyai peran yang sangat penting untuk menyampaikan informasi yang tepat mengenai kesehatan reproduksi. Jika seseorang remaja salah dalam memilih teman bergaul maka dapat mempengaruhi perilaku remaja khususnya dalam hal perilaku seksual.

Beberapa hasil penelitian di NTB bahwa prilaku seks aktif pra nikah pada remaja berisiko terhadap kehamilan remaja dan penularan penyakit menular seksual. Kehamilan yang tidak direncanakan pada remaja perempuan dapat berlanjut pada aborsi dan pernikahan remaja. Keduanya akan berdampak pada masa depan remaja tersebut, janin yang dikandung dan keluarganya.

Dari survey yang sama didapatkan alasan hubungan seksual pranikah tersebut sebagian besar karena penasaran/ingin tahu $(57,5 \%$ pria $)$, terjadi begitu saja (38,5\% perempuan), dan dipaksa oleh pasangan $(12,6 \%$ perempuan). Hal ini mencerminkan kurangnya pemahaman remaja tentang keterampilan hidup sehat, resiko hubungan seksual dan kemampuan untuk menolak hubungan yang tidak mereka inginkan (BKKBN BTV 2013).

Berdasarkan data BKKBN NTB 2013 , terdapat $38,37 \%$ perempuan yang menikah pertama diusia 10-19tahun. Sebanyak 29,5\% responden di Lombok Barat menikah dibawah 17tahun. Dari seluruh responden perempuan yang sudah menikah, 89,1\% mengatakan bahwa perkawinan adalah pilihan sendiri, lakilaki sebesar 80\%. Perkawinan anak dibawah 17tahun .

Berdasarkan observasi pendahuluan yang dilakukan peneliti, SMAN 9 Mataram merupakan salah satu sekolah favorit di kota mataram yang dulunya bernama SMKN 8 Mataram. Terdapat tiga kelas yaitu kelas X, XI, dan XII. Setiap kelas dibagi menjadi 8 ruangan yang isinya satu ruangan 24-35siswa, jumlah keseluruhan siswa dari kelas X, XI, dan XII berjumlah 652 orang. Siswa-siswi SMAN 9 Mataram rata-rata berasal dari keluarga ekonomi menengah dan beberapa berasal dari keluarga sederhana. Sehingga pergaulan remaja di SMAN 9 Mataram biasanya mengikuti kelas ekonomi dari masing-masing keluarga.

Berdasarkan masalah yang terjadi cukup banyak siswa atau siswi yang berhenti sekolah karena hubungan seksual pranikah dan menyebabkan kehamilan diluar nikah.

Upaya yang dilakukan untuk mencegah atau mengurangi terjadinya peningkatan masalah pada remaja yaitu dalam hal ini hubungan seksual pranikah dengan memberikan penyuluhan tentang kesehatan reproduksi remaja, membagikan leaflet tentang kesehatan reproduksi remaja. Memberikan pelatihan tentang konselor sebaya serta pemanfaatan pusat informasi dan konseling kesehatan reproduksi remaja (BKKBN Provinsi NTB, 2013). 


\section{BAHAN DAN METODE}

Desain penelitian ini menggunakan deskriptifanalitik dengan pendekatan cross sectional. Penelitian ini dilaksanakan tanggal 07 Januari sampai 11 Januari 2019. Populasi pada penelitian ini adalah siswa/siswi kelas X. MIA I dan XI. B SMAN 9 Mataram. Sampel berjumlah 60 responden dengan tehnik sampling menggunakan total sampling. Instrument pengumpulan data dengan menggunakan lembar kuisioner. Uji statistik menggunakan uji spearman rank dengan menggunakan SPSS.

HASIL

Tabel 1 Distribusi responden berdasarkan jenis kelamin

\begin{tabular}{|c|l|l|l|}
\hline NO & \multicolumn{1}{|c|}{$\begin{array}{c}\text { JENIS } \\
\text { KELAMIN }\end{array}$} & $\begin{array}{c}\text { FREKUENSI } \\
(\mathrm{n})\end{array}$ & $\begin{array}{c}\text { PERSENTASE } \\
(\%)\end{array}$ \\
\hline 1 & LAKI-LAKI & 28 & 46,67 \\
\hline 2 & PEREMPUAN & 32 & 53,33 \\
\hline & JUMLAH & $\mathbf{6 0}$ & $\mathbf{1 0 0}$ \\
\hline
\end{tabular}

SUMBER : Data Primer, 2019

Berdasarkan tabel di atas menunjukan bahwa responden dengan jenis kelamin perempuan memiliki persentase terbanyak 32 responden $(53,33 \%)$.

\section{Tabel 2 Distribusi responden} berdasarkan kelas

\begin{tabular}{|c|c|l|l|}
\hline NO & KELAS & $\begin{array}{c}\text { FREKUENSI } \\
(\mathrm{n})\end{array}$ & $\begin{array}{c}\text { PERSENTASE } \\
(\%)\end{array}$ \\
\hline 1 & X. MIA & 30 & 50 \\
\hline 2 & XI. B & 30 & 50 \\
\hline & JUMLAH & $\mathbf{6 0}$ & $\mathbf{1 0 0}$ \\
\hline
\end{tabular}

SUMBER : Data Primer, 2019

Berdasarkan tabel di atas menunjukan bahwa responden kelas X. MIA 1 sebanyak 30 responden $(50 \%)$, dan responden kelas XI. B sebanyak 30 responden $(50 \%)$.
Tabel 3 Peer Review tentang pengetahuan kesehatan reproduksi

\begin{tabular}{|l|l|l|l|}
\hline NO & KRITERIA & $\begin{array}{c}\text { FREKUENSI } \\
(\mathrm{n})\end{array}$ & $\begin{array}{c}\text { PERSENTASE } \\
(\%)\end{array}$ \\
\hline 1 & BAIK & 26 & 43,33 \\
\hline 2 & CUKUP & 25 & 41,67 \\
\hline 3 & KURANG & 9 & 15 \\
\hline \multicolumn{2}{|c|}{ JUMLAH } & $\mathbf{6 0}$ & $\mathbf{1 0 0}$ \\
\hline
\end{tabular}

SUMBER : Data Primer, 2019

Berdasarkan tabel di atas menunjukan bahwa peer review tentang kesehatan reproduksi memiliki kriteria baik sebanyak 26 responden $(43,33 \%)$.

Tabel 4 Sikap remaja tentang seksual pranikah

\begin{tabular}{|l|l|l|l|}
\hline NO & KRITERIA & $\begin{array}{c}\text { FREKUENSI } \\
(\mathrm{n})\end{array}$ & $\begin{array}{c}\text { PERSENTASE } \\
(\%)\end{array}$ \\
\hline 1 & BAIK & 38 & 63,33 \\
\hline 2 & CUKUP & 15 & 25 \\
\hline 3 & KURANG & 7 & 11,67 \\
\hline \multicolumn{2}{|c|}{ JUMLAH } & $\mathbf{6 0}$ & $\mathbf{1 0 0}$ \\
\hline
\end{tabular}

SUMBER : Data Primer, 2019

Berdasarkan tabel di atas menunjukan bahwa sikap seksual tentang seksual pranikah responden yang memiliki kriteria baik sebanyak 38 responden $(63,33 \%)$.

\section{PEMBAHASAN}

Penelitian ini dilakukan pada kelas X. MIA 1 dan XI.B, populasi dari siswa/i kelas X. MIA 1 dan XI.B yaitu 60 orang, dan yang menjadi sampel dalam penelitian ini adalah 60responden.

Berdasarkan tabel 1 menunjukan jenis kelamin perempuan lebih dominan dengan jumlah 32 responden $(53,33 \%)$ dan lakilaki dengan jumlah 28 responden $(46,67 \%)$.

Berdasarkan tabel 1 jumlah perempuan lebih banyak karena perempuan lebih dominan di sekolah tersebut.Menurut penelitian yang dipublikasikan Prosiding National Academy Of Sciences menunjukan hal menarik, kemampuan bertahan hidup 
perempuan lebih baik justru setelah lahir. Artinya resiko meninggal di kandungan pada janin perempuan sebenarnya lebih besar.

Berdasarkan tabel 3 menunjukan bahwa setelah diberikan kuisioner peer review tentang kesehatan reproduksi siswa/i sebagian besar pada kriteria baik yaitu sebanyak 26 responden $(43,33 \%)$, responden yang memiliki kriteria cukup sebanyak 25 responden $(41,67 \%)$, dan responden yang memiliki kriteria kurang sebanyak 9 responden (15\%). Hal ini salah satunya disebabkan oleh informasi yang didapatkan siswa/i sudah cukup baik.

Sesuai dengan teori yang dikemukakan oleh Kirchler (1990, dalam buku Castiogiovani(2000) mengatakan teman sesama remaja adalah sekolompok kecil individu yang memiliki kesamaan usia, hampir seperti teman dekat dan saling berbagi aktivitas yang sama. Peran penting teman sebaya pada remaja sangat critical (remaja sudah mulai kritis dalam menyampaikan dan menerima informasi) yaitu bahwa hubungan dengan teman sebaya akan mendekati prototype (sesuai dengan bertambahnya usia dari anak-anak ke masa remaja, maka terjadi pula perubahan dari sifat dasar anak/remaja dalam berprilaku dan menerima informasi) hubungan pada saat dewasa nanti seperti hubungan sosial di pekerjaan dan interaksi dengan lawan jenis.

Berdasarkan tabel 4 menunjukan bahwa sikap remaja tentang seksual pranikah setelah diberikan kuisioner siswa/i sebagian besar pada kriteria baik sebanyak 36 responden.

Sesuai dengan perkembangan usia dari anak-anak menjadi remaja maka terjadi pula perkembangan pada organorgan reproduksi terutama organ-organ reproduksi eksterna, sehingga remaja mulai mencari tahu informasi tentang perubahan-perubahan yang terjadi pada dirinya baik mencari informasi dari orang tua maupuun teman sebaya. Terjadinya perkembangan atau perubahan organ- organ reproduksi serta informasi yang didapat oleh remaja akan berpengaruh pada prilaku remaja tersebut, remaja mulai merasa malu dan mulai membedakan diri antara laki-laki dan perempuan.

Dalam masa ini, prilaku seksual juga ikut mewarnai kehidupan para remaja. Perilaku seksual yang dimaksud adalah segala tingkah laku yang didorong oleh hasrat seksual, baik dengan lawan jenis maupun dengan sesama jenis.

\section{KESIMPULAN}

Terdapat pengaruh antara peer review tentang kesehatan reproduksi terhadap sikap remaja tentang seksual ranikah di SMAN 9 Mataram. 


\section{DAFTAR PUSTAKA}

BKKBN NTB 2013. Keluarga Berencana, Kesehatan Reproduksi, Gender dan Pembangunan Kependudukan

Castigiovani. 2000. Adolescents and their peer groups: A study on the significance of peers, social categorization processes and coping with developmental tasks

Dariyo, A. 2010. Psikologi Perkembangan Remaja. Galio Indonesia: Bogor

DEPKES RI 2013. Kesehatan Reproduksi

Dikes Kota Mataram 2013. Perkembangan Organ Reproduksi Remaja

Dikes Provinsi NTB 2009. Data Kasus Kumulatif HIV/AIDS di Provinsi NTB Tahun 1992-2009

Eny Kusmirah 2006. Hubungan peran teman sebagai sumber informasi kesehatan reproduksi dengan sikap remaja mengenai hubungan seksual pranikah. Program pasca sarjana Universitas Gadjah Mada: Yogyakarta

Gunarsa, S. D. 2008. Psikologi perkembangan anak dan remaja. Remaja Rosdakarya; Jakarta

PKBI Provonsi NTB 2013. Remaja, Data dan Fakta

Riyanto. 2009. http;//tarmizi.word press. Com/pola-asuh-orang tua-dalammengarahkan-perilaku-anak. Tanggal 26, jam 11.00

Yusuf, H. S. 2009. Psikologi Perkembangan Anak Dan Remaja. Remaja Rosdakarya: Bandung 